\title{
SGLT2 Inhibitors: Slowing of Chronic Kidney Disease Progression in Type 2 Diabetes
}

David C. Wheeler · June James · Dipesh Patel · Adie Viljoen ·

Amar Ali - Marc Evans - Kevin Fernando · Debbie Hicks •

Nicola Milne $\cdot$ Philip Newland-Jones · John Wilding $\cdot$ as part of the Improving Diabetes Steering Committee

Received: August 3, 2020 / Accepted: September 11, 2020 / Published online: September 29, 2020

(C) The Author(s) 2020

\section{ABSTRACT}

Diabetic kidney disease (DKD) is a topic of increasing concern among clinicians involved in the management of type 2 diabetes mellitus (T2DM). It is a progressive and costly complication associated with increased risk of adverse cardiovascular (CV) and renal outcomes and mortality. Ongoing monitoring of the estimated glomerular filtration (eGFR) rate alongside the

Digital Features To view digital features for this article go to https://doi.org/10.6084/m9.figshare.12937334.

Electronic supplementary material The online version of this article (https://doi.org/10.1007/s13300020-00930-x) contains supplementary material, which is available to authorized users.

D. C. Wheeler · D. Patel

University College London, London, UK

J. James

University Hospitals of Leicester NHS Trust,

University of Leicester, Leicester, UK

A. Viljoen

Lister Hospital, Stevenage, UK

A. Ali

Oakenhurst Medical Practice, Blackburn, UK

M. Evans

University Hospital Llandough, Penarth, UK

K. Fernando

North Berwick Health Centre, North Berwick, UK urine albumin:creatinine ratio (ACR) is recommended during regular T2DM reviews to enable a prompt DKD diagnosis or to assess disease progression, providing an understanding of adverse risk for each individual. Many people with DKD will progress to end-stage kidney disease (ESKD), requiring renal replacement therapy (RRT), typically haemodialysis or kidney transplantation. A range of lifestyle and pharmacological interventions is recommended to help lower CV risk, slow the advancement of DKD and prevent or delay the need for RRT. Emerging evidence concerning sodium-glucose co-transporter-2 inhibitor (SGLT2i) agents suggests a role for these medicines in slowing eGFR decline, enabling regression of albuminuria and reducing progression to ESKD. Improvements in renal end

\section{Hicks}

Medicus Health Partners, Enfield, UK

N. Milne

Manchester University NHS Foundation Trust,

Manchester, UK

P. Newland-Jones

University Hospitals Southampton NHS Foundation

Trust, Southampton, UK

J. Wilding $(\bowtie)$

University of Liverpool, Liverpool, UK

e-mail: J.P.H.Wilding@liverpool.ac.uk 
points observed in SGLT2i CV outcome trials (CVOTs) highlighted the possible impact of these agents in the management of DKD. Data from the canagliflozin CREDENCE trial (Canagliflozin and Renal Events in Diabetes with Established Nephropathy Clinical Evaluation) have since demonstrated the effectiveness of this medicine in reducing the risk of kidney failure and $\mathrm{CV}$ events in a population comprising individuals with T2DM and renal disease. CREDENCE was the first SGLT2i study to examine renal outcomes as the primary end point. Realworld studies have reaffirmed these outcomes in routine clinical practice. This article summarises the evidence regarding the use of SGLT2 $i$ medicines in slowing the progression of DKD and examines the possible mechanisms underpinning the renoprotective effects of these agents. The relevant national and international guidance for monitoring and treatment of DKD is also highlighted to help clinicians working to support this vulnerable group.

Keywords: Chronic kidney disease; Diabetic kidney disease; End-stage kidney disease; Kidney failure; Oral glucose-lowering medicines; SGLT2 inhibitors; Type 2 diabetes

\section{Key Summary Points}

People with type 2 diabetes mellitus (T2DM) and diabetic kidney disease (DKD) are at increased risk of mortality alongside adverse cardiovascular (CV) and renal outcomes, with many progressing to endstage kidney disease and requiring haemodialysis or kidney transplantation

In recent years, a growing body of evidence has emerged concerning the potential renoprotective effects of the sodium-glucose co-transporter 2 inhibitor (SGLT2i) class of medicines, with data from large T2DM CV outcome trials (CVOTS) demonstrating a significant reduction in markers for progression of kidney disease in addition to $\mathrm{CV}$ end points
In response, a new era of SGLT2i cardiorenal studies was initiated, with the canagliflozin CREDENCE trial (Canagliflozin and Renal Events in Diabetes with Established Nephropathy Clinical Evaluation) being the first to publish data demonstrating the effectiveness of this medicine in reducing the risk of both kidney failure and CV events in a population comprising individuals with T2DM and renal disease

The evolving evidence base in this area is reflected in the latest international guidelines for the treatment of T2DM, and this article aims to put these recommendations into context for clinicians supporting people with T2DM, outlining the relevant studies that have driven these changes and examining the potential mechanisms that may underly the renoprotective effect of SGLT2i treatments as well as the implications for clinical practice

The SGLT2i Prescribing Tool, previously developed by the Steering Committee, has also been updated to reflect much of the evidence discussed in this review and is available via the Diabetes Therapy website as a supplementary material

\section{ROLE OF THE IMPROVING DIABETES STEERING COMMITTEE}

The Improving Diabetes Steering Committee comprises a panel of clinical experts from across primary and specialist care, who meet with the objective of improving diabetes care. The Committee aims to ensure that healthcare professionals (HCPs) who prescribe diabetes medicines have access to balanced and accurate information and evidence concerning type 2 diabetes mellitus (T2DM) medicines, with a specific focus on the sodium-glucose co-transporter-2 inhibitor (SGLT2i) class of treatments. The group is committed to providing healthcare 
colleagues with clarity regarding the evidence base supporting SGLT2i agents, highlighting the relative benefits and risks of these therapies. Educational materials and publications, such as the previously published consensus documents, provided by the panel are intended to increase confidence and understanding regarding the appropriate place of these medicines within the current UK T2DM treatment paradigm $[1,2]$. Professor David Wheeler was involved with the planning, delivery, analysis and publication of the CREDENCE study, which included human participants and complied with the tenets of the Declaration of Helsinki.

\section{DIGITAL FEATURES}

This article is published with digital features to facilitate understanding of the article. You can access the digital features on the article's associated Figshare page. To view digital features for this article, go to https://doi.org/10.6084/m9. figshare.12937334.

\section{INTRODUCTION}

Diabetic kidney disease (DKD) is a widely recognised and growing concern among clinicians involved in the management of type 2 diabetes mellitus (T2DM). Practical approaches that prevent or delay the progression of this serious and costly condition are urgently required, particularly in the current era of COVID-19, for the benefit of people living with T2DM and healthcare services alike.

As the T2DM treatment pathway continues to evolve, an emerging role has been highlighted for SGLT2i therapies in slowing DKD progression to end-stage kidney disease (ESKD) $[3,4]$. In this article, the Improving Diabetes Steering Committee discusses current data and the proposed mechanisms that may underpin renoprotective effects of these agents, as well as the potential value that SGLT2i therapies offer in delaying the onset and progression of chronic kidney disease (CKD).

The SGLT2i Prescribing Tool, previously developed by the Steering Committee, has also been updated to reflect much of the evidence discussed here. The Tool is included as a supplementary item alongside this article and can also be accessed online via the Diabetes Therapy website. This article is based on previously conducted studies and does not contain any studies with human participants or animals performed by any of the authors.

\section{THE BURDEN OF KIDNEY DISEASE IN T2DM}

DKD is a sub-type of CKD observed in people with T2DM in the absence of other identified kidney pathologies. Approximately $40 \%$ of people with T2DM have kidney disease, and this is predicted to rise to around $50 \%$ by $2025[5,6]$. In recent years, there have been significant increases in the number of people living with T2DM and DKD, as well as the proportion of this population requiring renal replacement therapy (RRT); dialysis and/or kidney transplantation [7].

\section{Increased Mortality Due to DKD}

Kidney and cardiovascular (CV) functions are intrinsically linked. CKD is an independent predictor of $\mathrm{CV}$ disease and mortality, in both people with and without T2DM [8]. Increased mortality rates associated with $\mathrm{T} 2 \mathrm{DM}$ are believed to be predominantly due to kidney disease, and global disease burden data show that the number of deaths due to DKD rose by 94\% between the years 1990-2012 [8, 9].

\section{Quality of Life Outcomes with DKD}

Health-related quality of life (HRQoL) outcomes are progressively and significantly impaired with advancing CKD and DKD [10, 11]. Research examining HRQoL among people with kidney disease has shown that people with diabetes (particularly the elderly) are at greater risk of poor outcomes relating to physical functioning and emotional/mental health compared with those without diabetes $[10,11]$. 


\section{Economic Burden of DKD}

The rising number of people with DKD requiring RRT has significant implications for health resource use and costs of care for people with T2DM. Haemodialysis is estimated to cost the UK National Health Service (NHS) £26,835 per patient each year [12]. In 2010/2011, the NHS costs attributed to kidney failure due to T2DM were approximately $£ 379$ million, and this is projected to rise to around $£ 635$ million by 2035/36 [13].

Intensified T2DM treatment strategies, using lifestyle and pharmacological interventions to lower the risk of renal and CV outcomes, may reduce inpatient admissions and the mean cost per person-year compared with conventional disease management [14].

\section{EVALUATION AND CLASSIFICATION OF DKD DISEASE MARKERS}

Although much debate exists regarding the most appropriate and accurate markers for progression of DKD, a moderately increased urinary albumin:creatinine ratio (ACR) (albuminuria) and declining estimated glomerular filtration rate (eGFR) are currently regarded as the most acceptable and widely used early indicators of kidney disease in the absence of specific biomarkers and diagnostic tools $[3,15]$.

The National Institute for Health and Care Excellence (NICE) guidelines for the assessment and management of CKD classify the stages of kidney disease and define the risk of adverse outcomes (e.g. acute kidney injury, all-cause mortality, CV events) according to eGFR and ACR (shown in Fig. 1) [16]. Decreasing eGFR and increasing ACR are each considered to be independent risk factors for adverse outcomes and mortality [8, 16]. Elevated ACR and declining eGFR, in combination, multiply the risk of adverse outcomes [16]. The rate of eGFR decline over time also provides a signal for disease progression and an indication of prognosis $[17,18]$.

\section{Routine Monitoring of Renal Markers}

People with mild-to-moderate reductions in eGFR (Fig. 1, G2-G3a, eGFR 45-89 $\mathrm{ml} / \mathrm{min} / 1.73$ $\mathrm{m}^{2}$ ) and moderately increased ACR (Fig. 1, A2, ACR $3-30 \mathrm{mg} / \mathrm{mmol}$ ) should be tested/monitored at least once each year [16]. People at greater risk of adverse outcomes, classified by a moderate-to-severe eGFR decrease and severely

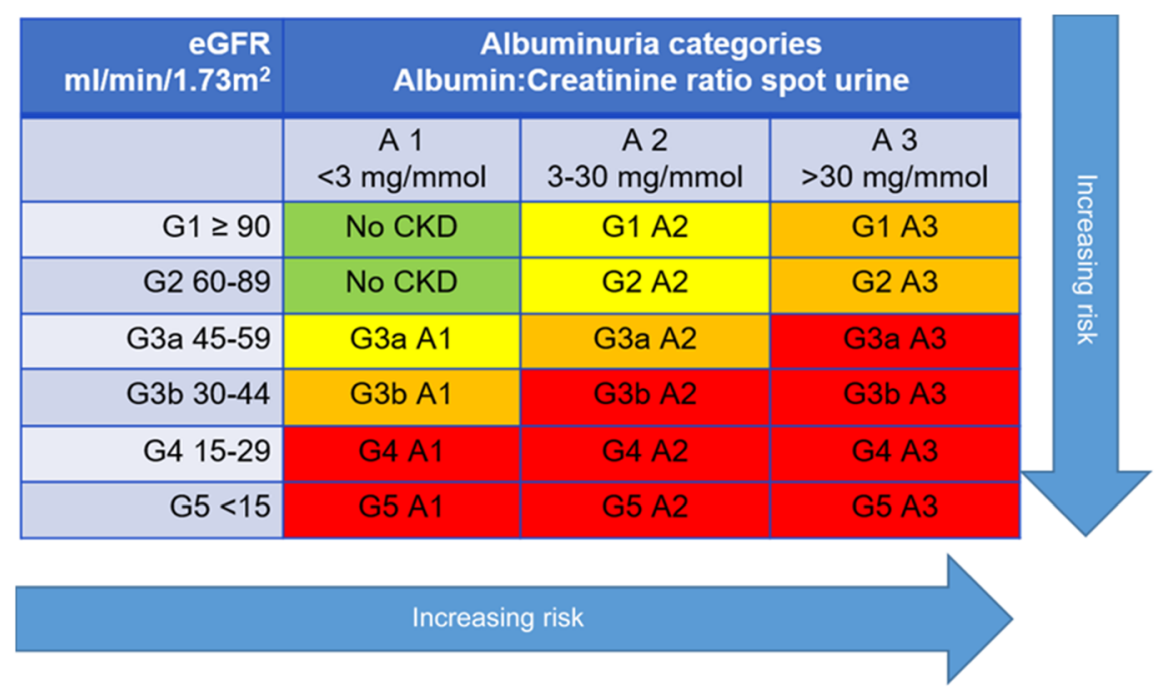

Adapted from National Institute for Health and are Excellence. Clinical guideline (CG182)

Fig. 1 NICE/KDIGO classification of CKD using eGFR and ACR categories [16] 
increased ACR (Fig. 1, G3b-G5 and A3, eGFR $<30 \mathrm{ml} / \mathrm{min} / 1.73 \mathrm{~m}^{2}$ and ACR $>30 \mathrm{mg} /$ $\mathrm{mmol})$, should be tested more frequently (2-4 times each year, depending on risk category) [16].

Although the 2019 General Medical Services (GMS) Quality Outcomes Framework (QOF) no longer requires regular measurement of ACR, six QOF points are awarded to practices establishing and maintaining a register of adults (aged $\geq 18$ years) with CKD (classified using the NICE recommendations G3a-G5) (CKD005) [19]. As adults with T2DM represent a significant proportion of this group, they should be included on local CKD registers, where appropriate.

\section{SLOWING OR PREVENTING DKD PROGRESSION}

\section{Addressing Risk Factors: Lifestyle and Pharmacological Interventions}

Several lifestyle and pharmacological approaches have been recommended to help prevent or delay the progression of DKD [16]. These are

Box 1 Key lifestyle and pharmacological interventions for DKD progression $[16,19,20,35]$

Diet and nutritional advice

Recommendations on appropriate levels of physical activity

Weight loss advice

Smoking cessation advice and support

Education on proteinuria levels and potential markers for kidney function decline

Education on the potential renal impact of over-thecounter medicines (e.g. NSAIDs)

Review of concomitantly prescribed medicines and the potential for adverse renal effects

ACEi or ARB therapy (maximally tolerated dose)

Statins

SGLT2i treatments summarised in Box 1. Guidelines include regular evaluation of kidney and/or vascular complications, as well as interventions that aim to improve glycaemic control and lipid levels, maintain healthy body weight and optimise blood pressure [16, 20]. Advice may incorporate adjustments to diet and exercise, management of stress or referral for smoking cessation support $[16,20]$.

Detailed dietary assessment (to address obesity), followed by appropriate support and education, can be a helpful first step toward slowing kidney function decline $[16,20]$. Encouragement to give up smoking, with cessation advice and pharmacological interventions (e.g. nicotine replacement therapy) where appropriate, may be helpful for patients who need extra support in this area. Regular reviews of HbA1c and prescribed glucose-lowering medications are also important. Other risk factors should be checked routinely, such as blood pressure and prescribing of appropriate antihypertensive drugs in line with national and local guidelines, usually angiotensin-converting enzyme inhibitors (ACEis) or angiotensin receptor blockers (ARBs) $[16,19,20]$. Statins are considered standard care for people with CKD in both primary and secondary prevention according to NICE guidelines [21]. Some concurrent medications may adversely affect renal function, e.g. nonsteroidal anti-inflammatory drugs (NSAIDS). It is necessary to review prescribed treatments and provide education on the use of over-thecounter (OTC) medications and their potential impact on the kidneys [16]. Recommendations on the use of aspirin and other anti-platelet medications in people with T2DM and kidney disease are unclear $[16,22]$. NICE guidelines for the management of T2DM do not recommend aspirin for people without CV disease and the NICE CKD guidelines highlight the need for additional evidence on the benefits of aspirin as a primary prevention measure for people with CKD at the highest risk of CV disease [16, 22]. 


\section{Renoprotective Medicines}

Agents that block the renin-angiotensin-aldosterone system (RAAS) pathway (ACEi and ARB drugs) have demonstrated renoprotective effects in people with T2DM [23, 24]. These medicines are recommended by NICE for slowing the progression of DKD and are included in the current QOF (DM006, 3 points) $[16,19]$. The Kidney Disease Improving Global Outcomes (KDIGO) group has also drafted guidelines for the management of CKD in people with diabetes (due to be published in September 2020) [20]. KDIGO recommends titration to the maximally tolerated dose of ACEi and ARB treatments for people with T2DM and increased ACR (ACR $>3 \mathrm{mg} / \mathrm{mmol}$ ) [20]. Many individuals with T2DM may already be taking ACEi or ARB medicines for hypertension. Monitoring for eGFR reduction and hyperkalaemia is required when initiating or increasing the dose of RAAS antagonists [16]. These drugs have been shown to reduce the relative risk of renal events by $20 \%$; however, a residual risk remains for people with T2DM [23-26]. The Steno-2 trial showed the benefit of intensive multifactorial treatment approaches (e.g. lifestyle changes, glycaemic control, RAAS inhibitors) on CV and renal outcomes in people with T2DM and severely increased ACR [26]. It should be noted that, despite multiple interventions, $25 \%$ of those treated intensively went on to develop kidney disease, suggesting that there is scope for improvement in this area of T2DM management [26].

Published evidence from large-scale randomised trials and real-world studies supports the use of SGLT2i treatments in reducing the overall rate of kidney function decline and adverse renal risk among those with T2DM [3, 27-34]. The American Diabetes Association (ADA) and European Association for the Study of Diabetes (EASD) consensus on the management of hyperglycaemia in T2DM (Fig. 2), the new KDIGO guideline and the European Society of Cardiology (ESC)/EASD guideline each recommend the use of SGLT2i treatments for people with T2DM and eGFR $\geq 30 \mathrm{ml} / \mathrm{min} / 1.73$ $\mathrm{m}^{2}$ (G3a/G3b, Fig. 1), where the approved licence indication allows $[20,35,36]$. These recommendations are based on subgroup analyses from SGLT2i cardiovascular outcome trials (CVOTs) as well as more recent data from the CREDENCE trial (Canagliflozin and Renal Events in Diabetes with Established Nephropathy Clinical Evaluation), the first published study to assess the effects of an SGLT2i agent on renal outcomes in patients with T2DM and CKD $[3,30,31]$.

\section{SGLT2i TREATMENTS: RENAL OUTCOMES DATA}

Data analyses examining the effects of SGLT2i therapies on renal function have shown a similar pattern regarding eGFR [3, 27-31, 34]. An initial acute reduction in eGFR is observed at the start of treatment, followed by an overall slowing in the decline of eGFR over time and a reduction in other markers of kidney function deterioration [3, 27-31, 34].

\section{Renal Data from SGLT2i Cardiovascular Outcome Trials}

The SGLT2i CVOTs primarily examined and demonstrated the efficacy of this treatment class in reducing $\mathrm{CV}$ risk among those with T2DM [27-29, 34]. However, secondary and exploratory analyses of these data highlighted a potential role for SGLT2i therapies in reducing adverse renal outcomes, even though the study populations were not generally considered to be at significant risk of advancing DKD [27-31, 34]. Table 1 shows the mean eGFR and urine ACR measures reported at baseline for each of the CVOTs. Mean eGFR at baseline was within the NICE category for mild risk (Fig. 1, G2) for each of the CVOTs $[16,27-31,34]$. Where provided within the published data, median urine ACR at baseline was within the normal range according to the NICE guidelines (Fig. 1, A1) [16, 27-31, 34].

Table 2 provides an overview of key renal end points and reported outcomes from each of the SGLT2i CVOTs. Due to differences in study design, renal efficacy outcomes cannot be directly compared across CVOTs. However, each 


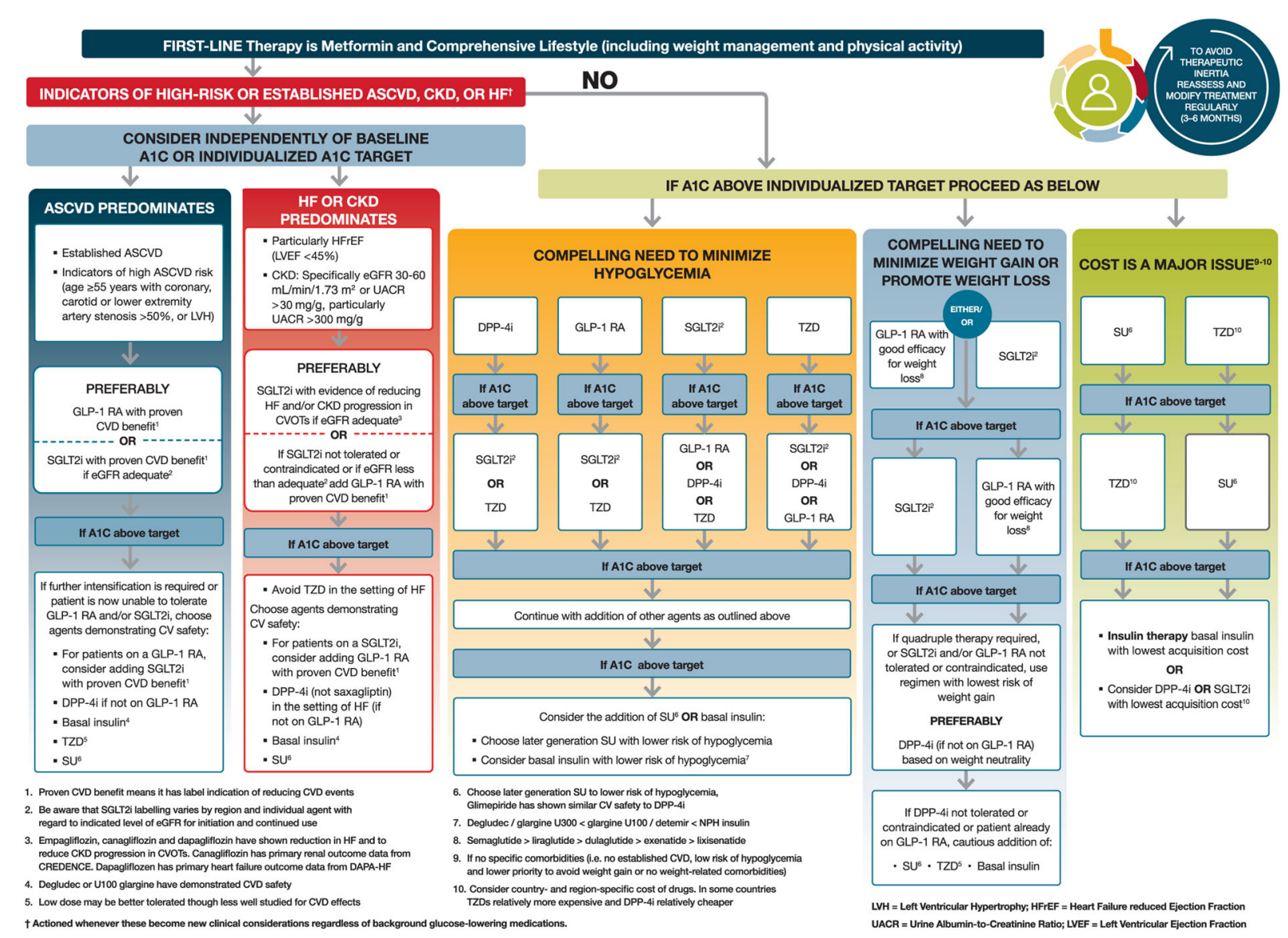

Fig. 2 ADA/EASD consensus on the management of hyperglycaemia in T2DM. Reproduced with permission from Davies et al. [35]

Table 1 Mean eGFR and median ACR scores at baseline reported in SGLT2i CVOTs [27-29, 34]

\begin{tabular}{lcl}
\hline SGLT2i CVOT & $\begin{array}{l}\text { Mean eGFR } \\
\text { at baseline }\end{array}$ & $\begin{array}{l}\text { Median urine } \\
\text { ACR at baseline }\end{array}$ \\
\hline EMPA-REG & $74 \mathrm{ml} / \mathrm{min} /$ & $2.03 \mathrm{mg} / \mathrm{mmol}$ \\
OUTCOME & $1.73 \mathrm{~m}^{2}$ & \\
(empagliflozin) & & \\
CANVAS Program & $76 \mathrm{ml} / \mathrm{min} /$ & $1.36 \mathrm{mg} / \mathrm{mmol}$ \\
(canagliflozin) & $1.73 \mathrm{~m}^{2}$ & \\
DECLARE-TIMI 58 & $85 \mathrm{ml} / \mathrm{min} /$ & $1.47 \mathrm{mg} / \mathrm{mmol}$ \\
(dapagliflozin) & $1.73 \mathrm{~m}{ }^{2}$ & \\
VERTIS-CV & $76 \mathrm{ml} / \mathrm{min}$ & Not available \\
(ertugliflozin) & per 1.73 & \\
& $\mathrm{~m}^{2}$ & \\
\hline
\end{tabular}

study demonstrated reductions in composite renal risk end points (Fig. 3) as well as individual markers of kidney function decline [28, 30, 31, 34].

Post-hoc analysis of data from the EMPAREG OUTCOME trial showed a reduced risk in the composite renal end point when comparing empagliflozin treatment with placebo, and the CANVAS Program renal composite end point occurred less frequently among participants in the canagliflozin group compared with those in the placebo group (Fig. 3; Table 2) [28]. Regression of albuminuria (return to ACR $\leq 3 \mathrm{mg}$ / $\mathrm{mmol}$ ) was increased by $30 \%$ in the CANVAS study (Table 2) [28, 30]. Analysis of data from the DECLARE-TIMI 58 trial revealed a reduced risk in the renal composite end point (with dapagliflozin treatment versus placebo), and the DAPA-CKD trial was halted early in March 2020 
Table 2 Summary of key renal outcomes reported in SGLT2i CVOTs [27-31, 34]

\section{CVOT key renal end points}

EMPA-REG OUTCOME (empagliflozin)

Composite renal outcome:

Doubling of serum creatinine level, initiation of RRT, death from renal disease

Incident or worsening of nephropathy:

Progression to severely increased ACR, doubling of serum creatinine levels accompanied by an eGFR $\leq 45 \mathrm{ml} / \mathrm{min} / 1.73 \mathrm{~m}^{2}$, initiation of RRT or death from renal disease

CANVAS Program (canagliflozin)

Composite renal outcome:

Sustained $40 \%$ reduction in eGFR, the need for RRT or death from renal causes

Progression of albuminuria (ACR $>3 \mathrm{mg} / \mathrm{mmol}$ )

Regression of albuminuria (return to ACR $\leq 3 \mathrm{mg} / \mathrm{mmol}$ )

\section{DECLARE-TIMI 58 (dapagliflozin)}

Renal composite outcome:

Sustained eGFR decline of $\geq 40 \%$ to $<60 \mathrm{ml} / \mathrm{min} / 1.73 \mathrm{~m}^{2}$, ESKD (dialysis for $\geq 90$ days, kidney transplantation or confirmed sustained eGFR $<15 \mathrm{ml} / \mathrm{min} / 1.73 \mathrm{~m}^{2}$ ) or death from renal causes

Cardiorenal end point:

Sustained eGFR decline of $\geq 40 \%$ to $<60 \mathrm{ml} / \mathrm{min} / 1.73 \mathrm{~m}^{2}$, ESKD (dialysis for $\geq 90$ days, kidney transplantation or confirmed sustained eGFR $<15 \mathrm{ml} / \mathrm{min} / 1.73 \mathrm{~m}^{2}$ ) or death from renal or CV causes

Sustained decline in eGFR $\left(\geq 40 \% \mathrm{ml} / \mathrm{min} / 1.73 \mathrm{~m}^{2}\right.$ to $<60 \mathrm{ml} / \mathrm{min} /$ $1.73 \mathrm{~m}^{2}$ )

Risk of ESKD or renal death

VERTIS-CV (ertugliflozin)

Renal composite outcome:

Renal death, RRT or doubling of serum creatinine
Reported outcome: SGLT2i therapy versus placebo

$46 \%$ relative risk reduction (HR 0.54, 95\%

CI $0.40-0.75 ; P<0.001)$

$39 \%$ relative risk reduction (HR 0.61; 95\%

CI $0.53-0.70 ; P<0.001)$

$40 \%$ relative risk reduction (HR 0.60; $95 \%$

CI $0.47-0.77$ )

$27 \%$ relative risk reduction (HR 0.73; 95\%

CI 0.67-0.79)

$30 \%$ regression

(HR 1.70; 95\% CI 1.51-1.91)

$47 \%$ relative risk reduction (HR 0.53; 95\%

CI $0.43-0.66 ; P<0.0001)$

$24 \%$ relative risk reduction

(HR 0.76; 95\% CI 0.67-0.87; $P<0.0001$

$46 \%$ relative risk reduction (HR 0.54; 95\%

CI $0.43-0.67 ; P<0.0001$ )

$59 \%$ relative risk reduction (HR 0.41; 95\%

CI $0.20-0.82 ; P=0.012$ )

$19 \%$ relative risk reduction

(HR 0.81; 95.8\% CI 0.63-1.04; $P=0.08$ ) 
A

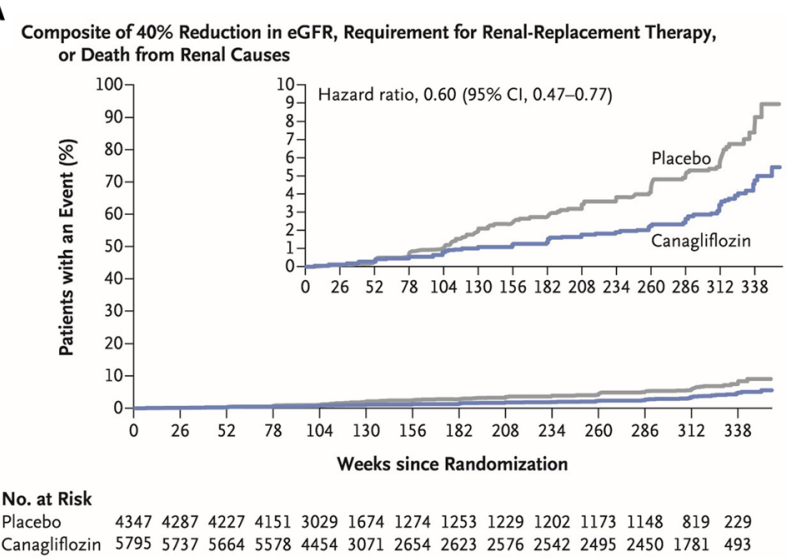

B

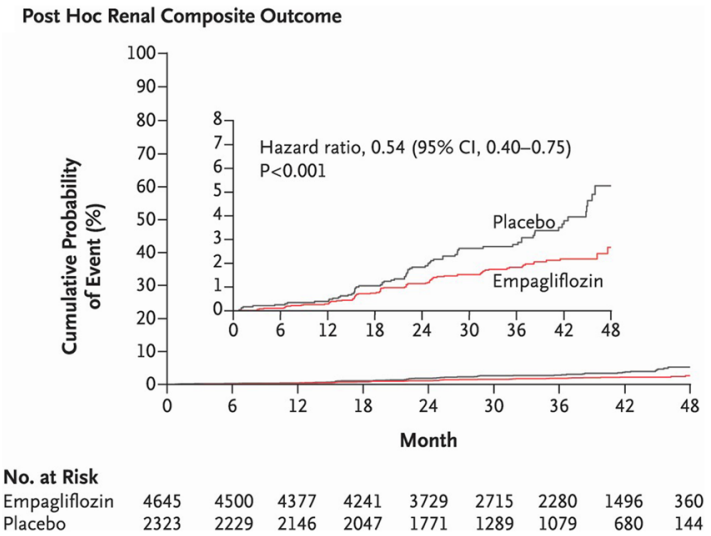

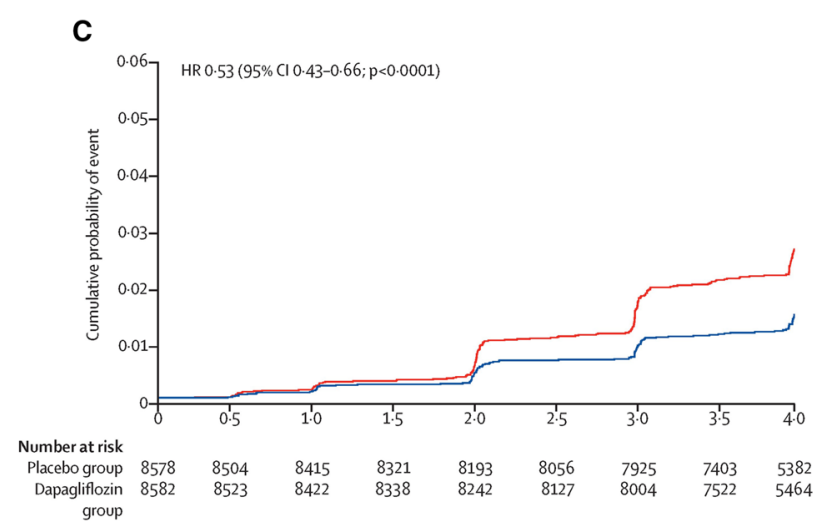

Fig. 3 Renal composite outcomes reported in SGLT2i CVOTs $[28,30,31]$. a EMPA-REG OUTCOME post hoc renal composite outcome (doubling serum creatinine level, initiation of RRT or death from renal disease). Reproduced with permission from Wanner et al. [30]. b The CANVAS Program exploratory renal composite outcome (40\% reduction in eGFR, requirement for RRT,

because of overwhelming efficacy [31]. The ertugliflozin VERTIS-CV trial demonstrated a $19 \%$ relative risk reduction with ertugliflozin for the composite renal end point, versus placebo, in people with T2DM and atherosclerotic cardiovascular disease (ASCVD) (Table 2) (and post hoc exploratory analysis using data from the VERTIS-SU and VERTIS-MET trials suggested that ertugliflozin provided improvements in eGFR and ACR compared with non-ertugliflozin treatment) [34, 37]. or death from renal causes). Reproduced with permission from Neal et al. [28]. c DECLARE-TIMI 58 secondary efficacy renal composite $(\geq 40 \%$ eGFR decline, ESKD, or death from renal causes). Reproduced with permission from Mosenzon et al. [31]

\section{The CREDENCE Trial}

The CREDENCE trial was a double-blind, randomised study to assess renal treatment outcomes with canagliflozin (100 mg) among adults with T2DM and CKD [3].

Participants were at least 30 years of age, with HbA1c levels of $47.5-107.7 \mathrm{mmol} / \mathrm{mol}$, CKD (defined as eGFR between $30-90 \mathrm{ml} / \mathrm{min} /$ $1.73 \mathrm{~m}^{2}$ ) and albuminuria (urine ACR 33.9-565 mg/mmol) [3]. Nearly all participants were receiving ACEi or ARB treatment and a prespecified plan ensured that $60 \%$ of 
Table 3 Summary of key renal outcomes reported in the canagliflozin CREDENCE trial [3]

\begin{tabular}{|c|c|}
\hline $\begin{array}{l}\text { CREDENCE key end } \\
\text { points measured }\end{array}$ & $\begin{array}{l}\text { Reported outcome: } \\
\text { canagliflozin versus } \\
\text { placebo }\end{array}$ \\
\hline $\begin{array}{l}\text { Primary composite } \\
\text { outcome: ESKD, } \\
\text { doubling of serum } \\
\text { creatinine level, or renal } \\
\text { or CV death }\end{array}$ & $\begin{array}{l}30 \% \text { relative risk reduction } \\
\quad(\mathrm{HR} 0.70 ; 95 \% \mathrm{CI} \\
0.59-0.82 ; P=0.00001)\end{array}$ \\
\hline $\begin{array}{l}\text { Renal-specific composite: } \\
\text { ESKD, doubling of the } \\
\text { serum creatinine level or } \\
\text { renal death }\end{array}$ & $\begin{array}{l}34 \% \text { relative risk reduction } \\
\quad(\mathrm{HR} 0.66 ; 95 \% \mathrm{CI}, \\
0.53-0.81 ; P<0.001)\end{array}$ \\
\hline $\begin{array}{l}\text { ESKD: Chronic dialysis } \\
\text { for } \geq 30 \text { days, kidney } \\
\text { transplantation, } \\
\text { eGFR }<15 \mathrm{ml} / \mathrm{min} / 1.73 \\
\mathrm{~m}^{2} \text { sustained } \\
\text { for } \geq 30 \text { days }\end{array}$ & $\begin{array}{l}32 \% \text { relative risk reduction } \\
\quad(\mathrm{HR} 0.68 ; 95 \% \mathrm{CI} \\
0.54-0.86 ; P=0.002)\end{array}$ \\
\hline $\begin{array}{l}\text { Doubling of serum } \\
\text { creatinine }\end{array}$ & $\begin{array}{l}40 \% \text { relative risk reduction } \\
\quad(\mathrm{HR} 0.60 ; 95 \% \mathrm{CI} \\
0.48-0.76 ; P<0.001)\end{array}$ \\
\hline $\begin{array}{l}\text { Dialysis, kidney } \\
\text { transplantation or renal } \\
\text { death }\end{array}$ & $\begin{array}{l}\text { 28\% relative risk reduction } \\
\quad(\mathrm{HR} 0.72 ; 95 \% \mathrm{CI} \\
0.54-0.97)\end{array}$ \\
\hline $\begin{array}{l}\text { CV composite: } \mathrm{CV} \text { death or } \\
\text { hospitalisation for heart } \\
\text { failure }\end{array}$ & $\begin{array}{l}31 \% \text { relative risk reduction } \\
\quad(\text { HR } 0.69 ; 95 \% \mathrm{CI} \\
0.57-0.83 ; P<0.001)\end{array}$ \\
\hline
\end{tabular}

participants had eGFR $<60 \mathrm{ml} / \mathrm{min} / 1.73 \mathrm{~m}^{2}$ [3] The study included 4401 participants and median follow-up was 2.62 years [3]. At baseline, the mean age was 63 years, mean HbA1c was $67 \mathrm{mmol} / \mathrm{mol}$, mean eGFR was $56.2 \mathrm{ml} /$ $\mathrm{min} / 1.73 \mathrm{~m}^{2}$ and median ACR was $104.75 \mathrm{mg} /$ mmol [3].

Key renal efficacy and safety end points from the CREDENCE study are summarised in Table 3. Figure 4 shows the primary composite outcome for this study: a renal composite comprising ESKD, doubling of serum creatinine

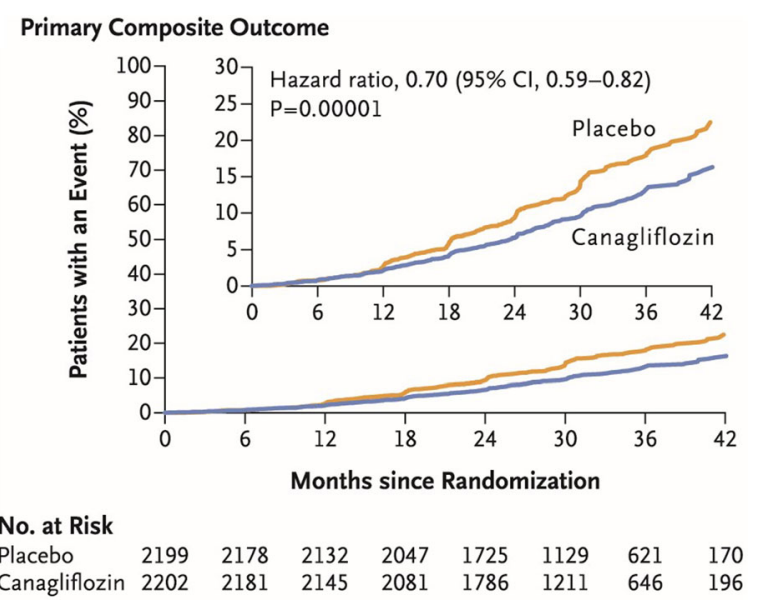

Fig. 4 Primary efficacy outcome from the CREDENCE trial. Renal composite outcome (end-stage kidney disease, doubling of serum creatinine, or renal or CV death). Reproduced with permission from Perkovic et al. [3]

level, or renal or CV death. The primary outcome event rate was significantly lower in the canagliflozin group compared with the placebo group: 43.2 versus 61.2 per 1000 patient-years, providing a $30 \%$ relative risk reduction (HR 0.70; 95\% CI 0.59-0.82; $P=0.00001$ ) [3].

The relative risk of the composite of ESKD, doubling of the serum creatinine level or renal death was 34\% lower in the canagliflozin group versus the placebo group (HR 0.66; 95\% CI 0.53-0.81; $P<0.001)$ [3]. The components of ESKD (chronic dialysis for $\geq 30$ days, kidney transplantation, eGFR $<15 \mathrm{ml} / \mathrm{min} / 1.73 \mathrm{~m}^{2}$ sustained for $\geq 30$ days) were reduced by $32 \%$ (HR 0.68; 95\% CI 0.54-0.86; $P=0.002$ ) and the risk of dialysis or kidney transplantation was reduced by $26 \%$ (HR $0.74 ; 95 \%$ CI $0.55-1.00$ ) [3].

The estimated number needed to treat (NNT) over 2.5 years for the primary composite end point was 22 , meaning that 47 fewer patients in a population of 1000 would reach this end point during this time frame compared with placebo [3]. Among participants with baseline eGFR $30-45 \mathrm{ml} / \mathrm{min} / 1.73 \mathrm{~m}^{2}$, the NNT over 2.5 years to prevent the primary composite end point was 16 [3].

As highlighted already, kidney disease is closely associated with increased $\mathrm{CV}$ risk and mortality [8]. The CREDENCE trial 
demonstrated that canagliflozin treatment was associated with a lower incidence of CV outcomes in this high-risk population, including the composite of $\mathrm{CV}$ death or hospitalisation for heart failure (HF) (HR 0.69; 95\% CI 0.57-0.83; $P<0.001$ ) [3]. The risk of CV death, myocardial infarction or stroke was reduced by $20 \%$ (HR 0.80; 95\% CI 0.67-0.95; $P=0.01$ ) [3].

In accordance with EMPA-REG and DECLARE safety data, no significant difference was observed in the risk of lower limb amputation (LLA) with canagliflozin treatment versus placebo in the CREDENCE study [3, 27, 29]. LLA rates were 12.3 and 11.2 per 1000 patient-years in the canagliflozin and placebo groups, respectively (HR 1.11; 95\% CI 0.79-1.56) [3]. A foot care protocol amendment was included in the CREDENCE study in response to a safety signal raised during the CANVAS Program; however, CREDENCE was already well underway at that stage with approximately $70 \%$ of participants enrolled in the study $[3,28]$. Rates of fracture were similar across the canagliflozin and placebo groups (HR 0.98; 95\% CI 0.70-1.37) [3]. As observed in CVOTs, the reported incidence of diabetic ketoacidosis (DKA) was low, but numerically higher in the SGLT2i group compared with placebo: 2.2 versus 0.2 per 1000 patient-years [3, 27-29].

It has been noted that CREDENCE is the only definitive prospective clinical trial to date that has demonstrated a clinically significant effect on major renal outcomes with an SGLT2i therapy in people with CKD and T2DM $[36,38]$.

\section{Meta-Analysis: SGLT2i CVOT and CREDENCE Trial Data}

Pooled renal data from a meta-analysis examining CV and renal outcomes from SGLT2i CVOTs and the CREDENCE trial showed that canagliflozin, empagliflozin and dapagliflozin were associated with favourable outcomes with respect to renal end points versus placebo [32].

Pooled relative risk (RR) among people with T2DM and CV disease or CV risk factors was lower for those treated with an SGLT2i compared with placebo for the composite renal outcome of doubling of serum creatinine or
$40 \%$ decrease in eGFR, initiation of RRT or death due to renal disease (RR 0.63; 95\% CI 0.56-0.71) [32]. The pooled RR for the same composite renal outcome among those with $\mathrm{CV}$ disease or CV risk factors and eGFR $<60 \mathrm{ml} /$ $\min / 1.73 \mathrm{~m}^{2}$ was also lower for those treated with an SGLT2i versus placebo (RR 0.67; 95\% CI 0.59-0.76) [32]. Progression of albuminuria among people with T2DM and CV disease or CV risk factors was reduced with SGLT2i treatment compared with placebo (RR 0.80; 95\% CI $0.76-0.84$ ) [32]. Progression of albuminuria was defined as a $\geq 30 \%$ increase in albuminuria or transition from either normo-albuminuria (Fig. 1, A1) to moderately increased albuminuria (microalbuminuria) (Fig. 1, A2) or severely increased albuminuria (macroalbuminuria) (Fig. 1, A3), or from moderately to severely increased albuminuria [32].

\section{Real-World Evidence}

A large, international, real-world study of people with T2DM (CVD-REAL 3) demonstrated that initiation of SGLT2i therapy was associated with a slower rate of kidney function decline and reduced risk of major kidney events compared with other glucose-lowering drugs [33]. Mean follow-up was 14.9 months and the main outcome measure was eGFR decline [33]. Pooled data showed a difference in eGFR decline favouring SGLT2i treatment compared with other glucose-lowering drugs of $1.53 \mathrm{ml} / \mathrm{min} /$ $1.73 \mathrm{~m}^{2}$ per year $(95 \%$ CI $1.34-1.72 ; P<0.0001)$ [33]. An additional kidney composite end point was used in the study, comprising a sustained reduction in eGFR of $\geq 50 \%$ or ESKD (defined as eGFR $<15 \mathrm{ml} / \mathrm{min} / 1.73 \quad \mathrm{~m}^{2}$ ), dialysis for $\geq 30$ days or kidney transplantation [33]. Overall, 351 composite kidney outcomes occurred: 114 in the SGLT2i group (3.0 events per 10,000 patient-years) and 237 among those taking other glucose-lowering medications (6.3 events per 10,000 patient-years) (HR $0.49 ; 95 \%$ CI 0.35-0.67; $P<0.0001$ ) [33].

A large register-based cohort study using nationwide data from routine clinical practice in Sweden, Denmark and Norway showed that SGLT2i treatment lowered the risk of serious 


\section{A Normal physiology}

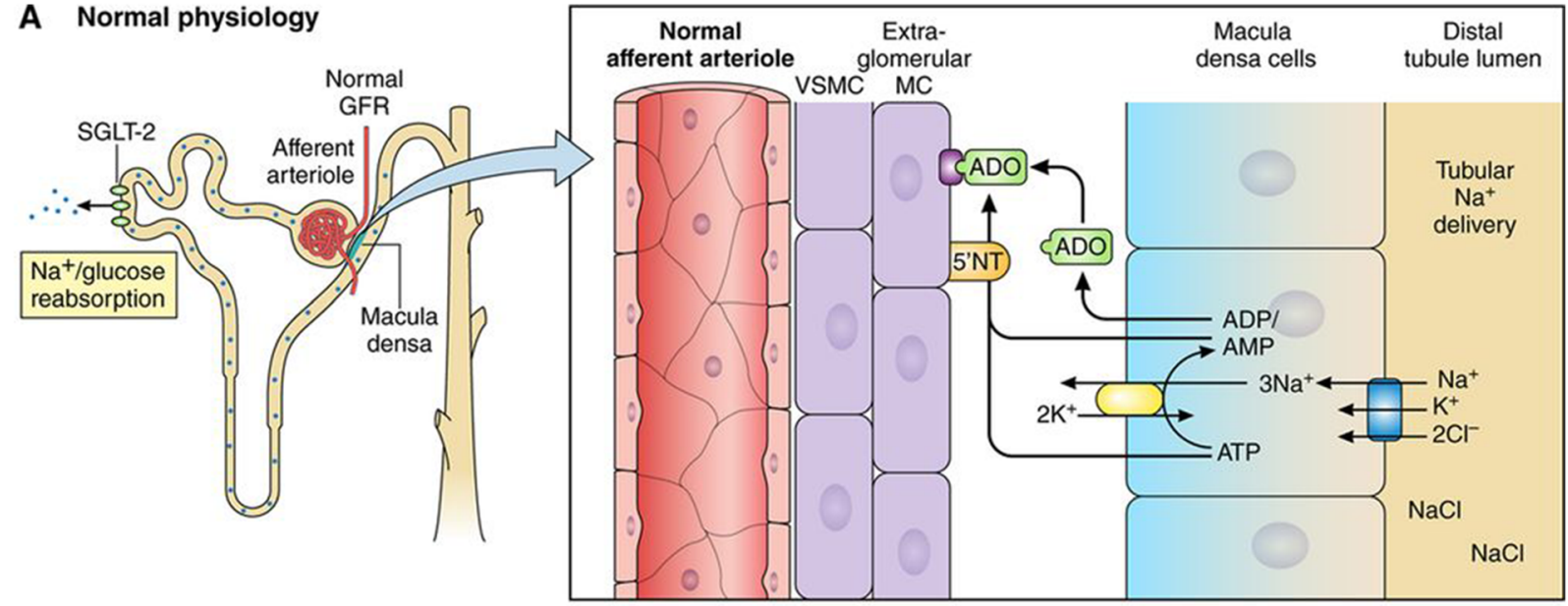

B Hyperfiltration in early stages of diabetic nephropathy

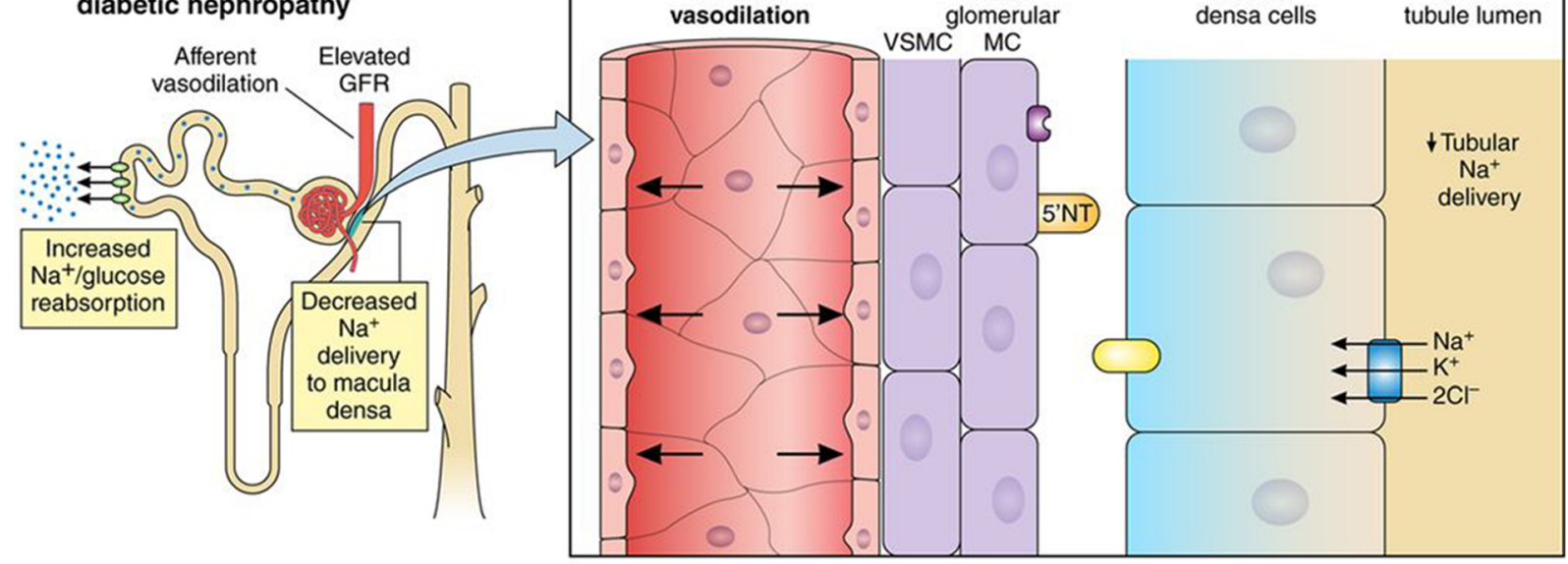

C SGLT-2 inhibition reduces hyperfiltration via TGF

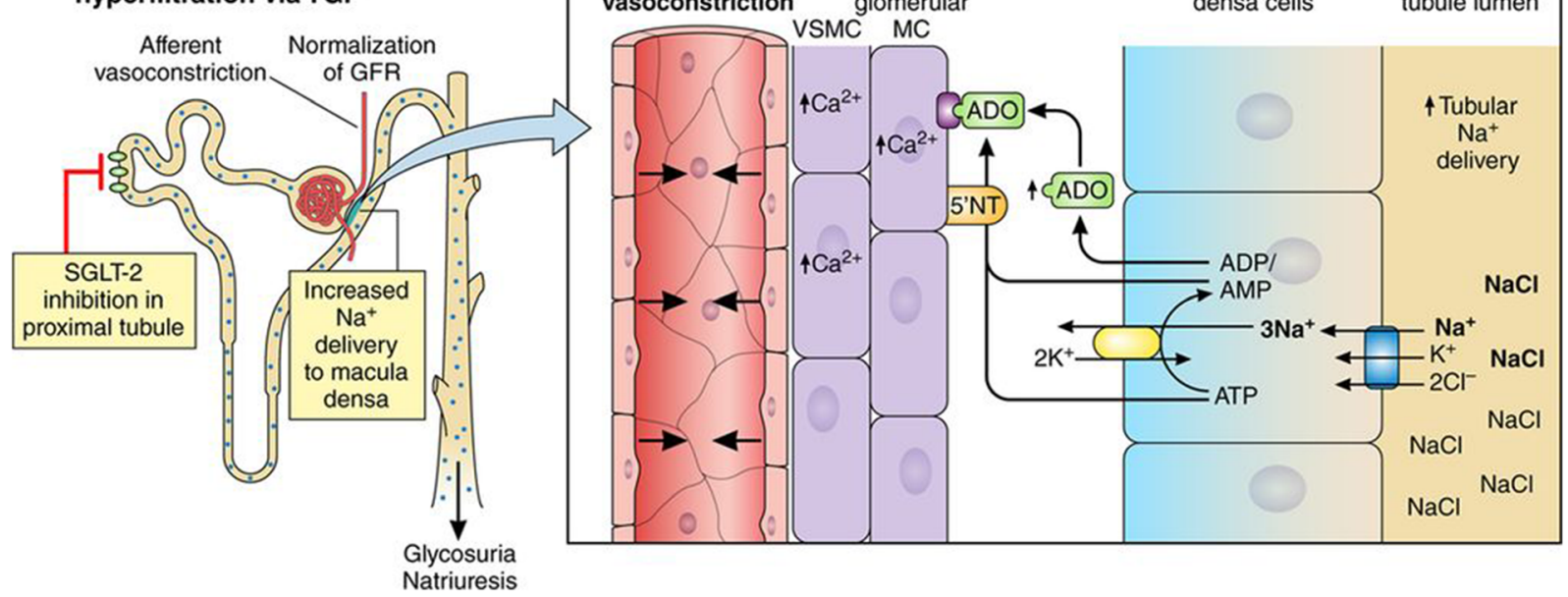


4Fig. 5 Proposed mechanism for sodium-mediated changes in adenosine bioactivity at the afferent arteriole. Reproduced with permission from Heerspink et al. [40]. a Mechanism under normal conditions. b Mechanism during hyperglycaemia. c Mechanism in the presence of an SGLT2i agent

renal events compared with dipeptidyl peptidase-4 inhibitor (DPP4i) therapies [39]. In total, 29,887 new SGLT2i users were included and matched with the same number of people newly initiated on DPP4i treatment [39]. Mean follow-up time was 1.7 years [39]. Incidence of serious renal events was 2.6 versus 6.2 events per 1000 person years with SGLT2i and DPP4i therapies, respectively (HR 0.42; 95\% CI 0.34-0.53) [39]. Incidence of RRT was also significantly reduced with SGLT2i treatment compared with DPP4is: 0.8 and 2.5 events per 1000 person years with SGLT2i and DPP4i therapies, respectively (HR $0.32 ; \quad 95 \%$ CI 0.22-0.47) [39].

\section{POTENTIAL MECHANISMS UNDERPINNING THE RENOPROTECTIVE ACTION OF SGLT2I TREATMENTS}

Conclusive evidence concerning the mechanisms responsible for the renoprotective effects observed with SGLT2i drugs is lacking, but several hypotheses have been proposed to explain the apparent slowing of DKD progression over time associated with these medicines. It is possible that a combination of several mechanisms may be responsible for the effect observed in practice $[4,40,41]$.

\section{Improved Glomerular Haemodynamics}

Figure 5 provides a visual representation of the processes outlined below. Tubuloglomerular feedback is mediated by the juxtaglomerular apparatus, which contains the macula densa; a specialised group of cells that detect sodium ion $\left(\mathrm{Na}^{+}\right)$concentration within the tubule, signalling to the glomerulus to regulate the filtration rate and avoid dehydration via a feedback loop. Changes in glomerular filtration are mediated by a signalling system involving adenosine generated by $\mathrm{Na}^{+} /$potassium $\left(\mathrm{K}^{+}\right)$ ATPase. Glucose and $\mathrm{Na}^{+}$are removed from the filtrate via SGLT2 co-transporter proteins in the proximal tubule $[4,41]$.

In the presence of hyperglycaemia due to diabetes, hyperfiltration occurs; SGLT2 cotransporters are upregulated in the proximal tubule and glucose and $\mathrm{Na}^{+}$reabsorption increases. Lower $\mathrm{Na}^{+}$concentrations are detected at the macula densa, which subsequently signals to the glomerulus to increase the filtration rate to restore $\mathrm{Na}^{+}$delivery to the distal tubule $[4,40,41]$. Adenosine levels drop due to reduced $\mathrm{Na}^{+} / \mathrm{K}^{+}$ATPase activity and the afferent arteriole dilates, enabling increased blood flow through the glomerulus [4, 40, 41].

The SGLT2i class of drugs reduces reabsorption of glucose and $\mathrm{Na}^{+}$via inhibition of SGLT2 co-transporters within the proximal tubule, which re-establishes $\mathrm{Na}^{+}$delivery to the macula densa $[4,40,41]$. Current models suggest that the afferent arteriole may constrict in response to raised adenosine levels, driven by increased membrane $\mathrm{Na}^{+} / \mathrm{K}^{+}$ATPase activity, to regulate and reduce glomerular blood flow [4, 40, 41]. It is possible that SGLT2i drugs have a protective effect on the glomerulus in the longer term due to the constriction of the afferent arteriole, which in turn lowers the intraglomerular pressure and reduces the amount of protein filtered through the glomerulus (albuminuria). It has also been suggested that RAASi therapies might have a complementary and renoprotective effect on intraglomerular pressure through dilation of the efferent arteriole, although subgroup analysis of CVOT data does not appear to support this hypothesis [40, 42].

\section{Reduced Tubular Workload}

Oxygen consumption is high in the kidney due to the many active functions associated with solute reabsorption [43, 44]. Increased SGLT2 co-transporter activity within the diabetic kidney raises the oxygen demand, which may not be matched by delivery to the tissue via the 
blood, leading to hypoxia [44]. The SGLT2i treatments may help to protect the kidneys by inhibiting reabsorption via these demanding co-transporters and reducing both the energy and aerobic requirements of the system [43].

\section{Reduced Renal Inflammation}

An additional mechanistic proposal is that SGLT2i agents reduce inflammation and hypoxic injury in the kidney over time [40]. Prolonged albuminuria and high intracellular glucose levels within proximal tubular cells trigger the expression of inflammatory cytokines, growth factors and fibrotic mediators as well as the production of reactive oxygen species $[4,44]$. As SGLT2i agents block uptake of glucose within proximal tubular cells, it is possible that their renoprotective effect may be partly due to a reduced local inflammatory response and fibrosis [4].

\section{IMPLICATIONS FOR CLINICAL PRACTICE}

\section{Efficient Care Provision and Use of Health Resources}

Progression of DKD represents a significant burden to healthcare services. Adapting care pathways to protect those most at risk of worsening kidney function has the potential to reduce this expensive complication of T2DM and may enable some people to avoid RRT completely. In addition, slowing the progression of DKD sufficiently to allow a significant proportion of high-risk individuals to defer dialysis or kidney transplant may provide considerable HRQoL improvements.

\section{Measurement and Ongoing Monitoring of DKD Markers for Progression}

In line with NICE guidelines, regular eGFR and ACR testing are essential for successful DKD diagnosis and monitoring. The rate of change or decline is also an important indicator of renal disease progression. In practice, it might not be possible to accurately measure the rate of decline as appropriate systems and software may not be widely available in primary care to support this. However, regular monitoring can help to reveal trends that are indicative of advancing kidney disease and poor prognosis. Early detection of CKD can facilitate the introduction of lifestyle and pharmacological interventions that enable people with T2DM to retain kidney function for as long as possible.

\section{Empowering People with T2DM and Those Who Care for Them}

Patient empowerment is critical to effective T2DM management and the avoidance of complications. It is important that people with T2DM receive education to help them understand the importance of their annual eGFR and urine ACR test in evaluating their current level of risk concerning $\mathrm{CV}$ complications and renal failure. Practical tools and materials are available via organisations such as Diabetes UK and TREND-UK to help support these conversations (e.g. Diabetes UK Information Prescriptions).

\section{Evidence- and Guideline-Based Use of SGLT2i Agents and Other Treatments}

ACEi and ARB treatments are recommended for their renoprotective attributes. These medicines should be considered for those with increased risk of renal and CV disease (with hypertension and/or microalbuminuria), where appropriate, and in accordance with NICE and local prescribing guidelines [16, 19-21]. Although, as mentioned previously, clinicians should keep in mind the residual risk for people with T2DM and monitor regularly for disease progression [23-26].

The ADA/EASD guidelines already reflect the growing evidence base for SGT2i medicines in the treatment of people with T2DM who may be at risk of DKD, and the latest KDIGO guidelines are aligned with these recommendations $[20,35]$. ESC/EASD guidelines also recognise the value of the CREDENCE data in demonstrating the renoprotective effects of canagliflozin [36]. The prescribing landscape is beginning to 
change; canagliflozin has been granted a change of licence by the European Medicines Agency (EMA) and UK Medicines and Healthcare products Regulatory Agency (MHRA) to include use in those with eGFR $<30 \mathrm{ml} / \mathrm{min} / 1.73 \mathrm{~m}^{2}$ [45]. This is in recognition of the renal outcomes demonstrated in SGLT2i CVOTs, the CREDENCE study and CVD-REAL 3 [3, 28, 30-34, 45-48]. Currently, canagliflozin has the most direct evidence for renal benefit in patients with DKD [3]. CREDENCE was the first published SGLT2i study specifically examining renal outcomes in a high-risk population, providing confirmatory and robust data on the effects of canagliflozin on patient-relevant renal end points $[3,38]$. There was no signal for adverse effects of amputation or fracture, which had been seen in the CANVAS trial [3, 28]. Studies on other SGLT2i therapies are ongoing, with data expected in the coming years (e.g. DAPA-CKD and EMPA-KIDNEY studies). These studies will assess whether the renal effects observed in the CREDENCE study are a consistent class effect across this group of therapies [3, 45-48].

\section{CONCLUSION}

Looking to the future, clinicians working across primary care, diabetes services and renal services will need to collaborate effectively with commissioners to ensure that the diagnosis and ongoing management of DKD are prioritised and that colleagues are appropriately supported to implement this work. Equitable access to testing and monitoring services, alongside the medications that have been shown to be effective in slowing the progression of $\mathrm{DKD}$, will be critical in protecting this vulnerable group and stemming the ever-increasing costs and HRQoL implications of kidney failure and RRT.

\section{ACKNOWLEDGEMENTS}

The Improving Diabetes Steering Committee thank Steve Bain (Swansea University) for his contribution to the expert panel meeting, which informed the development of this article, and his feedback on the manuscript content.

Funding. Napp Pharmaceuticals has fully funded the creation of this manuscript and has reviewed and certified it for technical accuracy. The journals rapid service fee was also funded by Napp Pharmaceuticals.

Authorship. All named authors meet the International Committee of Medical Journal Editors (ICMJE) criteria for authorship for this manuscript, take responsibility for the integrity of the work as a whole, and have given final approval for the version to be published. All authors had full access to all of the data in this study and take complete responsibility for the integrity of the data and accuracy of the data analysis.

Medical Writing and Editorial Assistance. This publication has been independently developed by the Improving Diabetes Steering Committee, with medical writing services provided on behalf of the authors by Rebecca Down at Copperfox Communications Limited and Clark Health Communications, and was funded by Napp Pharmaceuticals.

Disclosures. Professor David C Wheeler has received honoraria, consultancy fees, lecture fees and/or travel support from Amgen, AstraZeneca, Astellas, Boehringer Ingelheim, GlaxoSmithKline, Janssen, Lilly, Napp Pharmaceuticals, Mundipharma, Merck Sharp and Dohme, Takeda and Vifor Fresenius. June James has received funding for provision of educational sessions, resources and attendance at advisory boards from AstraZeneca, BD, Boehringer Ingelheim, Janssen, Lilly, MSD, Napp Pharmaceuticals, Novo Nordisk and Sanofi, Abbott, Mylan, Neon Diagnostics and Nipro. June does not hold any shares in any pharmaceutical company. Dr Dipesh Patel has received educational sponsorship, lecture fees and/or advisory related honoraria from AstraZeneca, Boehringer Ingelheim, Janssen, Lilly, Napp Pharmaceuticals, Novo Nordisk, Sanofi, MSD and Takeda. Dr Adie Viljoen has conducted research studies funded by, served as advisor to 
and received lecture honoraria and travel support from Amgen, AstraZeneca, Boehringer Ingelheim, Lilly, MSD, Napp Pharmaceuticals, Novo Nordisk, Pfizer, Regeneron, Sanofi Aventis and Tosoh. Dr Amar Ali has received speaker honoraria from all current manufacturers of SGLT2 inhibitors: AstraZeneca, Janssen, Boehringer Ingelheim, Napp Pharmaceuticals and Merck. Dr Marc Evans has received research support from Novo Nordisk and Takeda. He has received speaker fees and honoraria from Boehringer Ingelheim, Janssen, MSD, Napp Pharmaceuticals, Novartis and Novo Nordisk. He is also the Editor-in-Chief of this journal. Dr Kevin Fernando has received speaker honoraria from all current manufacturers of SGLT2 inhibitors: AstraZeneca, Janssen, Boehringer Ingelheim, Napp Pharmaceuticals and Merck. Debbie Hicks has received speaker honoraria from Roche, Sanofi and Takeda. She has received speaker and advisory board honoraria from Abbott, AstraZeneca, B. Braun, BD, Boehringer Ingelheim, Gendius, GlucoRx, Janssen, Lifescan, Lilly, MSD, Mylan, Napp Pharmaceuticals, Novo Nordisk and Owen Mumford. Educational sponsorship has been provided by $\mathrm{BD}$, Boehringer Ingelheim, Lilly, MSD, Mylan, Novo Nordisk, Roche, Sanofi and Takeda. She has also received conference registration and subsistence from BD, Lilly and Novo Nordisk. Debbie does not hold any shares in any pharmaceutical company. Nicola Milne has received funding for provision of educational sessions or attendance at advisory boards from AstraZeneca, BD, Boehringer Ingelheim, Janssen, Lilly, MSD, Napp Pharmaceuticals, Novo Nordisk, Roche, Takeda and Mylan. She has received travel grants to attend conferences from AstraZeneca, Boehringer Ingelheim, Novo Nordisk, Napp Pharmaceuticals, Novartis and Sanofi. Professor John Wilding has received funding for providing educational sessions and/or attending advisory boards from Astellas, AstraZeneca, Biologix, Boehringer Ingelheim, Janssen, Lilly, Merck, Mundipharma, Napp Pharmaceuticals, Novo Nordisk, Orexigen, Sanofi and Takeda. He has received travel grants to attend conferences from AstraZeneca, Boehringer Ingelheim, Lilly, Napp Pharmaceuticals, Novo Nordisk and Sanofi. He has received institutional research grant support or funding for clinical trials from AstraZeneca, Boehringer Ingelheim, Janssen, Novo Nordisk, Sanofi and Takeda.

Compliance with Ethics Guidelines. This article is based on previously conducted studies and does not contain any studies with human participants or animals performed by any of the authors.

Open Access. This article is licensed under a Creative Commons Attribution-NonCommercial 4.0 International License, which permits any non-commercial use, sharing, adaptation, distribution and reproduction in any medium or format, as long as you give appropriate credit to the original author(s) and the source, provide a link to the Creative Commons licence, and indicate if changes were made. The images or other third party material in this article are included in the article's Creative Commons licence, unless indicated otherwise in a credit line to the material. If material is not included in the article's Creative Commons licence and your intended use is not permitted by statutory regulation or exceeds the permitted use, you will need to obtain permission directly from the copyright holder. To view a copy of this licence, visit http:// creativecommons.org/licenses/by-nc/4.0/.

\section{REFERENCES}

1. Wilding J, Fernando K, Milne N, et al. SGLT2 inhibitors in type 2 diabetes management: key evidence and implications for clinical practice. Diabetes Ther. 2018;9:1757-73.

2. Ali A, Bain S, Hicks D, et al. SGLT2 inhibitors: cardiovascular benefits beyond HbA1c-translating evidence into practice. Diabetes Ther. 2019;10: 1595-622.

3. Perkovic V, Jardine MJ, Neal B, et al. Canagliflozin and renal outcomes in type 2 diabetes and nephropathy. N Engl J Med. 2019;38:2295-306.

4. Ito $\mathrm{M}$, Tanaka $\mathrm{T}$. The anticipated renoprotective effects of sodium-glucose cotransporter 2 inhibitors. Intern Med. 2018;57:2105-14. 
5. Wu B, Bell K, Stanford A, et al. Understanding CKD among patients with T2DM: prevalence, temporal trends, and treatment patterns-NHANES 2007-2012. BMJ Open Diabetes Res Care. 2016;4(1): e000154.

6. Kainz A, Hronsky M, Stel VS, et al. Prediction of prevalence of chronic kidney disease in diabetic patients in countries of the European Union up to 2025. Nephrol Dial Transplant. 2015;30(Suppl 4): 113-8.

7. Assogba FG, Couchoud C, Hannedouche T, et al. Trends in the epidemiology and care of diabetes mellitus-related end-stage renal disease in France, 2007-2011. Diabetologia. 2014;57:718-28.

8. Afkarian M, Sachs MC, Kestenbaum B, et al. Kidney disease and increased mortality risk in type 2 diabetes. J Am Soc Nephrol. 2013;24:302-8.

9. Alicic RZ, Rooney MT, Tuttle KR. Diabetic kidney disease: challenges, progress, and possibilities. Clin J Am Soc Nephrol. 2017;12:2032-45.

10. Aggarwal HK, Jain D, Pawar S, et al. Health-related quality of life in different stages of chronic kidney disease. QJM. 2016;109:711-6.

11. Kumar R, Krishan P, Jhajj R. Health-related quality of life and factors affecting it in type-2 diabetic nephropathy patients: a cross sectional observational study. Int J Res Med Sci. 2016;4:1511-7.

12. NHS Kidney Care. Chronic kidney disease in England: the human and financial cost. 2012. https:// www.england.nhs.uk/improvement-hub/wp-content/ uploads/sites/44/2017/11/Chronic-Kidney-Disease-inEngland-The-Human-and-Financial-Cost.pdf. Accessed July 2020.

13. Hex N, Bartlett C, Wright D, Taylor M, Varley D. Estimating the current and future costs of type 1 and type 2 diabetes in the UK, including direct health costs and indirect societal and productivity costs. Diabetes Med. 2012;29:855-62.

14. Gæde J, Oellgaard J, Ibsen R, et al. A cost analysis of intensified vs conventional multifactorial therapy in individuals with type 2 diabetes: a post hoc analysis of the Steno-2 study. Diabetologia. 2019;62:147-55.

15. Maclsaac RJ, Ekinci EI, Jerums G. Markers of and risk factors for the development and progression of diabetic kidney disease. Am J Kidney Dis. 2014;63: S39-62.

16. National Institute for Health and are Excellence. Clinical guideline (CG182). Chronic kidney disease in adults: assessment and management. 2015. https://www.nice.org.uk/guidance/cg182/resources/ chronic-kidney-disease-in-adults-assessment-andmanagement-pdf-35109809343205. Accessed July 2020.

17. Perkins RM, Bucaloiu ID, Kirchner HL, Ashouian N, Hartle JE, Yahya T. GFR decline and mortality risk among patients with chronic kidney disease. Clin J Am Soc Nephrol. 2011;6:1879-86.

18. Nojima J, Meguro S, Ohkawa N, Furukoshi M, Kawai $\mathrm{T}$, Itoh $\mathrm{H}$. One-year eGFR decline rate is a good predictor of prognosis of renal failure in patients with type 2 diabetes. Proc Jpn Acad Ser B Phys Biol Sci. 2017;93:746-54.

19. 2019/20 General Medical Services (GMS) contract Quality and Outcomes Framework (QOF). Guidance for GMS contract 2019/20 in England. 2019. https://www.england.nhs.uk/wp-content/uploads/ 2019/05/gms-contract-qof-guidance-april-2019.pdf. Accessed July 2020.

20. KDIGO clinical practice guideline on diabetes management in chronic kidney disease [public review draft] and Wedbinar. 2019. https://www. kdigo.org/guidelines/diabetes-ckd/. Accessed July 2020.

21. National Institute for Health and are Excellence. NICE guideline (CG181). Cardiovascular disease: risk assessment and reduction, including lipid modification. 2014. https://www.nice.org.uk/ guidance/cg181. Accessed July 2020.

22. National Institute for Health and are Excellence. Clinical guideline type 2 diabetes in adults: management (NG28). 2015. https://www.nice.org.uk/ guidance/ng28. Accessed July 2020.

23. Brenner BM, Cooper ME, de Zeeuw D, et al. Effects of losartan on renal and cardiovascular outcomes in patients with type 2 diabetes and nephropathy. N Engl J Med. 2001;345:861-9.

24. Lewis EJ, Hunsicker LG, Clarke WR, et al. Renoprotective effect of the angiotensin-receptor antagonist irbesartan in patients with nephropathy due to type 2 diabetes. N Engl J Med. 2001;345:851-60.

25. de Zeeuw D, Heerspink HJL. Unmet need in diabetic nephropathy: failed drugs or trials? Lancet Diabetes Endocrinol. 2016;4:638-40.

26. Muskiet MHA, Tonneijck L, Smits MM, et al. Pleiotropic effects of type 2 diabetes management strategies on renal risk factors. Lancet Diabetes Endocrinol. 2015;3:367-81.

27. Zinman B, Wanner C, Lachin JM, et al. Empagliflozin, cardiovascular outcomes, and mortality in type 2 diabetes. N Engl J Med. 2015;373:2117-288. 
28. Neal B, Perkovic V, Mahaffey KW, et al. Canagliflozin and cardiovascular and renal events in type 2 diabetes. N Engl J Med. 2017;377:644-57.

29. Wiviott SD, Raz I, Bonaca MP, et al. Dapagliflozin and cardiovascular outcomes in type 2 diabetes. N Engl J Med. 2019;380:347-57.

30. Wanner C, Inzucchi SE, Lachin JM, et al. Empagliflozin and progression of kidney disease in type 2 diabetes. N Engl J Med. 2016;375:323-34.

31. Mosenzon O, Wiviott SD, Cahn A, et al. Effects of dapagliflozin on development and progression of kidney disease in patients with type 2 diabetes: an analysis from the DECLARE-TIMI 58 randomised trial. Lancet Diabetes Endocrinol. 2019;7:606-17.

32. Lo KB, Gul F, Ram P, Kluger AY, et al. The effects of SGLT2 inhibitors on cardiovascular and renal outcomes in diabetic patients: a systematic review and meta-analysis. Cardiorenal Med. 2020;10:1-10.

33. Heerspink HJL, Karasik A, Thuresson M, et al. Kidney outcomes associated with use of SGLT2 inhibitors in real-world clinical practice (CVD-REAL 3): a multinational observational cohort study. Lancet Diabetes Endocrinol. 2020;8:27-35.

34. Cannon CP, McGuire DK, Pratley R, et al. The VERTIS CV trial. Cardiovascular outcomes following ertugliflozin treatment in patients with type 2 diabetes mellitus and atherosclerotic cardiovascular disease. Presented during American Diabetes Association (ADA) Virtual 88th Scientific Sessions. 2020. https://www.acc.org/education-and-meetings/imageand-slide-gallery/media-detail?id=307A7E103BC04A 588A3370709253FC35. Accessed July 2020.

35. Davies MJ, D'Alessio DA, Fradkin JM, et al. Management of hyperglycemia in type 2 diabetes, 2018. Consensus report by the American Diabetes Association (ADA) and the European Association for the Study of Diabetes (EASD). Diabetes Care. 2018;2018(41):2669-701.

36. Cosentino F, Grant PJ, Aboyans V, et al. 2019 ESC Guidelines on diabetes, pre-diabetes, and cardiovascular diseases developed in collaboration with the EASD. Eur Heart J. 2020;41:255-32323.

37. Cherney DZI, Heerspink HJL, Frederich R, et al. Effects of ertugliflozin on renal function over 104 weeks of treatment: a post hoc analysis of two randomised controlled trials. Diabetologia. 2020;63:1128-40.

38. Schernthaner G, Groop PH, Kalra PA, Ronco C, Taal MW. Sodium-glucose linked transporter-2 inhibitor renal outcome modification in type 2 diabetes: Evidence from studies in patients with high or low renal risk. Diabetes Obes Metab. 2020;22:1024.

39. Pasternak B, Wintzell V, Melbye M, et al. Use of sodium-glucose co-transporter 2 inhibitors and risk of serious renal events: Scandinavian cohort study. BMJ. 2020;369:m1186.

40. Heerspink HJ, Perkins BA, Fitchett DH, Husain M, Cherney DZ. Sodium glucose cotransporter 2 inhibitors in the treatment of diabetes mellitus: cardiovascular and kidney effects, potential mechanisms, and clinical applications. Circulation. 2016;134:752-72.

41. Cherney DZ, Perkins BA, Soleymanlou N, et al. Renal hemodynamic effect of sodium-glucose cotransporter 2 inhibition in patients with type 1 diabetes mellitus. Circulation. 2014;129:587-97.

42. Scholtes RA, van Raalte DH, Correa-Rotter R, et al. The effects of dapagliflozin on cardio-renal risk factors in patients with type 2 diabetes with or without renin-angiotensin system inhibitor treatment: a post hoc analysis. Diabetes Obes Metab. 2020;22:549-56.

43. Vallon V. The proximal tubule in the pathophysiology of the diabetic kidney. AJP Regul Integr Comp Physiol. 2011;300:R1009-R10221022.

44. Hansell P, Welch WJ, Blantz RC, Palm F. Determinants of kidney oxygen consumption and their relationship to tissue oxygen tension in diabetes and hypertension. Clin Exp Pharmacol Physiol. 2013;40:123-37.

45. Napp Pharmaceuticals Limited. Canagliflozin summary of product characteristics. 2020. https://www. medicines.org.uk/emc/product/8855/smpc. Accessed July 2020.

46. Boehringer Ingelheim Limited. Empagliflozin: summary of product characteristics. 2019. https:// www.medicines.org.uk/emc/product/5441/smpc. Accessed July 2020.

47. AstraZeneca UK Limited. Dapagliflozin summary of product characteristics. 2020. https://www. medicines.org.uk/emc/product/7607/smpc. Accessed July 2020.

48. Merck Sharp and Dohme Limited. Ertugliflozin summary of product characteristics. 2019. https:// www.medicines.org.uk/emc/product/10099/smpc. Accessed July 2020. 